\title{
Evaluation of Solidification Cracking Susceptibility for Austenitic Stainless Steel during Laser Trans-Varestraint Test Using Two- dimensional Temperature Measurement
}

\author{
Dan WANG, Kota KADOI, ${ }^{*}$ Kenji SHINOZAKI and Motomichi YAMAMOTO \\ Graduate School of Engineering, Hiroshima Univ., 1-4-1 Kagamiyama, Higashi-Hiroshima, Hiroshima, $739-8527$ Japan. \\ (Received on May 20, 2016; accepted on July 22, 2016; J-STAGE Advance published date: October 4, \\ 2016)
}

\begin{abstract}
Laser beam welding at high speeds enhances solidification cracking susceptibility, and brittleness temperature range must be measured under a high cooling rate to quantitatively evaluate the influence of welding speed upon the susceptibility. This work investigated the influence of welding speed upon the solidification cracking susceptibility of type 310 S stainless steel using the laser Trans-Varestraint test. A multi-sensor camera based on two-color thermometry measured two-dimensional temperature distribution around the molten pool to obtain the temperature range along different solidification crack directions, and the applicability and accuracy of the two-dimensional temperature distribution technique for measuring temperature range of cracks was investigated. The brittleness temperature range was measured precisely with this method; it was nearly constant around $102^{\circ} \mathrm{C}$ at welding speeds from 0.2 to $2.0 \mathrm{~m} / \mathrm{min}$. The results demonstrated the effect of the welding speed from 0.2 to $2.0 \mathrm{~m} / \mathrm{min}$ upon the solidification cracking susceptibility was very small.
\end{abstract}

KEY WORDS: solidification cracking susceptibility; in-situ observation; Trans-Varestraint test; two-dimensional temperature measurement; laser welding; brittleness temperature range.

\section{Introduction}

Laser beam welding (LBW) possesses a high energy density, a high welding speed and other advantages that cause lower distortion, provide high efficiency and high productivity, and has already been introduced to the heavy industries. ${ }^{1}$ ) Because solidification behavior and thermal strain depend upon welding speed, an increase in welding speed should cause materials to be more susceptible to solidification cracking. ${ }^{2)}$ However, the solidification cracking susceptibility during LBW is still under the discussion. Therefore, quantitative evaluation of the cracking susceptibility is required to prevent cracking from occurring.

Solidification crack occurs in the brittleness temperature range (BTR) wherein the ductility of the material deteriorates in the 'mushy zone' where liquid and solid phases coexist. ${ }^{3)}$ Thus, the BTR is an important factor for quantitative evaluation of the susceptibility. Trans-Varestraint test is one of the most common test methods to evaluate hot cracking susceptibility during welding, and can measure the BTR using the maximum crack length and the temperature profile. Conventionally, gas tungsten arc welding (GTAW) with a low welding speed has been applied as a heat source for the test. ${ }^{4}$ ) To apply laser welding to the Trans-Varestraint test instead, improvement of the conventional evaluation

\footnotetext{
* Corresponding author: E-mail: kadoi@hiroshima-u.ac.jp DOI: http://dx.doi.org/10.2355/isijinternational.ISIJINT-2016-302
}

methods is required, such as the measurement of the temperature profile, because the cooling rate during LBW is much higher than that of GTAW.

However, there are few studies of the Trans-Varestraint test with LBW at present. Chun et al. have reported that the BTR tended to decrease with increasing welding speeds from 0.6 to $2.4 \mathrm{~m} / \mathrm{min}$ during the laser Trans-Varestraint test for type $310 \mathrm{~S}$ stainless steel. ${ }^{5)}$ However, the BTR was measured using a thermocouple with a relative low response rate, providing a result that was less accurate than the method used herein. In addition, the authors (Wang et al., 2015) have previously developed a laser Trans-Varestraint test at different welding speeds from 0.2 to $2.0 \mathrm{~m} / \mathrm{min}$, and the BTR could be measured by applying an optical fiber radiation thermometer with a relative high response rate at welding speed of $0.2 \mathrm{~m} / \mathrm{min}$. However, at high welding speed over $1.5 \mathrm{~m} / \mathrm{min}$, the BTR could not be obtained because the stable temperature profile could not be measured due to the high cooling rate. Moreover, the longest solidification crack initiated at the sides of the molten pool at welding speeds greater than $1.0 \mathrm{~m} / \mathrm{min}$, making it difficult to measure the true BTR by only measuring one-dimensional temperature distribution along the welding direction.

A two-dimensional (2D) temperature distribution measurement method is one of candidates for measuring the true BTR. A multi-sensor camera based on a two-color thermometer can measure the 2D temperature distribution, with advantages such as in-situ observation, small measurement 
size, high temperature range measurement, and non-contact measurement. The authors have shown that this method enables the measurement of the 2D temperature distribution around the molten pool for type 310 S stainless steel. ${ }^{6}$ )

In this paper, the influence of the welding speed upon the solidification cracking susceptibility during LBW was investigated quantitatively. First, the 2D temperature distribution around the molten pool was measured using a multi-sensor camera during LBW. After which the applicability and accuracy of the 2D temperature distribution measurement for measuring the temperature range of the crack was investigated quantitatively. Finally, the BTR was measured by applying the Trans-Varestraint test with LBW at different welding speeds from 0.2 to $2.0 \mathrm{~m} / \mathrm{min}$ and the 2D temperature measurement method.

\section{Materials Used and Experimental Procedure}

\subsection{Materials Used}

Type 310 S stainless steel was used with the length $\times$ width $\times$ thickness dimensions of $110 \times 110 \times 5 \mathrm{~mm}^{3}$ and with the chemical composition listed in Table 1.

\subsection{Laser Trans-Varestraint Test}

The Trans-Varestraint test (VF-09-17F by Japan special machine) with LBW was carried out to evaluate solidification cracking susceptibility, and Table 2 lists the LBW conditions. A fibre laser (YLR-3000S by IPG Photonics. Ltd) was applied as a heat source, and the welding speed was varied from 0.2 to $2.0 \mathrm{~m} / \mathrm{min}$ as an experimental parameter. The laser power was adjusted to obtain half penetration in the thickness direction, which required laser power values of $1.0 \mathrm{~kW}$ for a welding speed of $0.2 \mathrm{~m} / \mathrm{min}, 1.85 \mathrm{~kW}$ for $1.0 \mathrm{~m} / \mathrm{min}, 2.25 \mathrm{~kW}$ for $1.5 \mathrm{~m} / \mathrm{min}$ and $2.5 \mathrm{~kW}$ for $2.0 \mathrm{~m} / \mathrm{min}$, respectively. The laser spot size was $0.4 \mathrm{~mm}$ (just focus) and the laser head was tilted $25^{\circ}$ to the welding direction to prevent interference with a high-speed camera (MEMERCAM HX-3 by nac) setup. While, Ar gas was blown at $50 \mathrm{l} / \mathrm{min}$ onto the surface and rear of the specimen during LBW. During the laser Trans-Varestraint test, when the trail edge of the molten pool moved to the center of the specimen, an augmented strain was loaded on the specimen by bending. At this point, the laser welding stopped and the solidification crack occurred simultaneously. The applied augmented strain were 2.8 and $4.3 \%$ using bending blocks with vari-

Table 1. Chemical composition of Type $310 \mathrm{~S}$ (mass\%)

\begin{tabular}{ccccccccc}
\hline $\mathrm{C}$ & $\mathrm{Si}$ & $\mathrm{Mn}$ & $\mathrm{P}$ & $\mathrm{S}$ & $\mathrm{Ni}$ & $\mathrm{Cr}$ & $\mathrm{Co}$ & $\mathrm{Fe}$ \\
\hline 0.04 & 0.43 & 0.96 & 0.019 & 0.001 & 20.13 & 25.19 & 0.09 & Bal. \\
\hline
\end{tabular}

Table 2. Laser beam welding conditions.

\begin{tabular}{lcccc}
\hline Welding speed, m/min & 0.2 & 1.0 & 1.5 & 2.0 \\
\hline Laser power, $\mathrm{kW}$ & 1.00 & 1.85 & 2.25 & 2.50 \\
Laser spot size, $\mathrm{mm}$ & 0.4 (just focus) & & \\
Laser irradiation angle, deg & 25 & & \\
Ar shielding gas, $1 / \mathrm{min}$ & 50 & & \\
\hline
\end{tabular}

ous surface radii because the saturated augmented strain was more than $2.0 \%{ }^{7)}$ During the laser Trans-Varestraint test, a high-speed camera was set up vertical to the center of the specimen to capture the molten pool shape after the solidification crack occurrence, using laser lighting to obtain clear images. After the tests, the number and length of the solidification cracks were measured using scanning electron microscopy (SEM). In addition, the test was taken two times at each condition to obtain credible data.

\subsection{Two-dimensional Temperature Measurement Using a Multi-sensor Camera}

Figure 1 shows a schematic illustration of the multisensor camera (DensitoCam-multi by Mitsui Photonics. Ltd) used for the 2D temperature measurement. An in-situ observation image could be obtained using one sensor and its corresponding $980 \mathrm{~nm}$ band-pass filter, while a 2D temperature distribution image could be obtained using two sensors set up with 650 and $800 \mathrm{~nm}$ band-pass filters with the temperature calculated based on two-color radiation thermometry. A detail description of the measurement principle and method have been reported elsewhere by the authors. ${ }^{8}$ Figure 2 shows the experiment setup of the 2D temperature measurement using the multi-sensor camera, which is vertically fixed to the specimen to capture the molten pool shape and measure the $2 \mathrm{D}$ temperature distribution. The welding condition is same as that of the laser Trans-Varestraint test but without any applied augmented strain during the temperature measurement. The shooting condition is given in Table $\mathbf{3}$.

\section{Experimental Results and Discussion}

\subsection{Two-dimensional Temperature Distribution Using the Multi-sensor Camera}

Figure 3 shows the in-situ observation image, 2D temperature distribution image and different temperature gradients obtained using the multi-sensor camera during LBW at welding speed of $0.2 \mathrm{~m} / \mathrm{min}$. During the temperature measurement, the molten pool backend shape and the $2 \mathrm{D}$ temperature distribution could be obtained simultaneously. However, due to the relatively large molten pool size, the measurement area of temperature distribution is only half of the molten pool. The fusion boundary of the molten pool is determined from the in-situ observation image, as shown

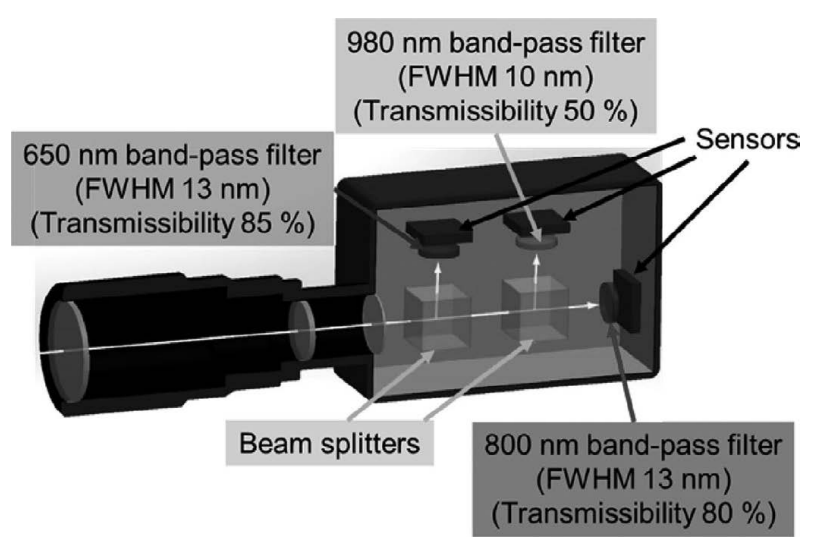

Fig. 1. Schematic illustration of a multi-sensor camera. 


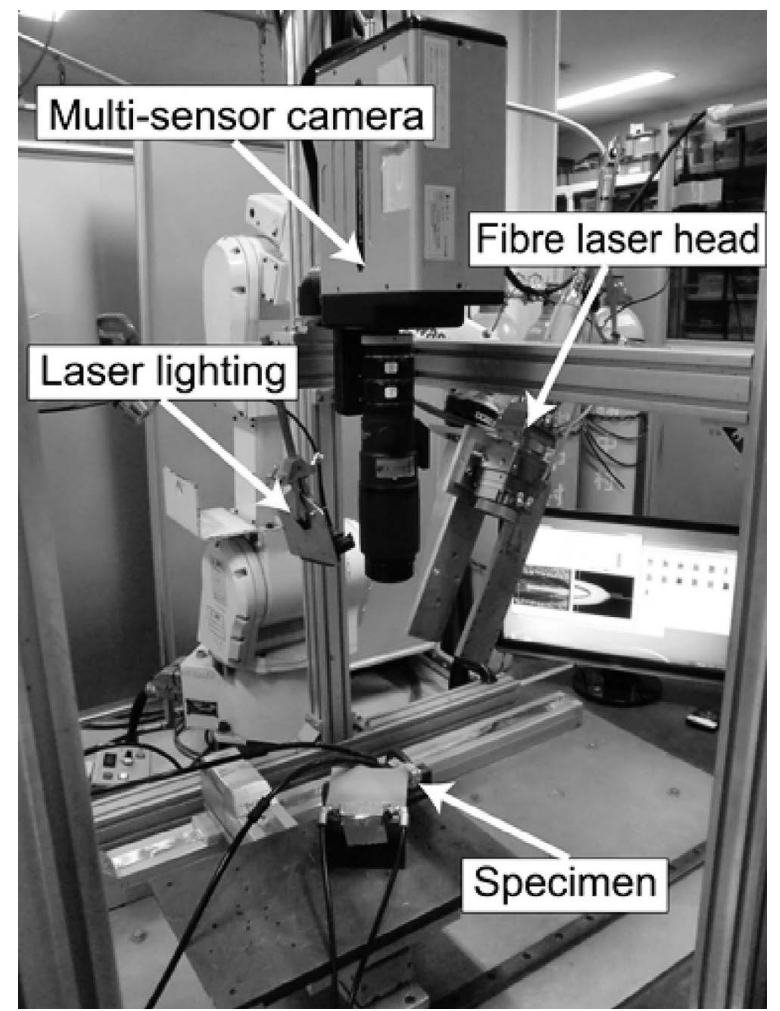

Fig. 2. Experiment setup of temperature measurement using a multi-sensor camera.

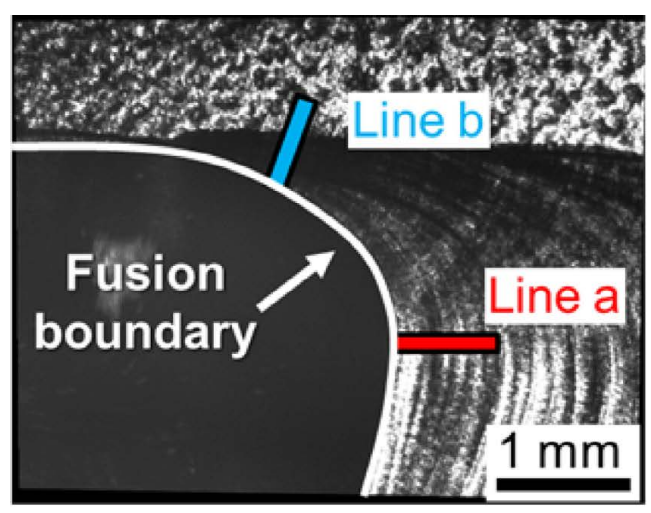

(a) In-situ observation image in Fig. 3(a), and the temperature gradients along different directions around the molten pool are measured using the 2D temperature distribution image, as shown in Fig. 3(b). Figure 3(c) indicates the comparison of different temperature gradients along centerline (line a) and the side (line b) of the molten pool, where the temperature gradients of line $\mathrm{a}$ and $\mathrm{b}$ are 254 and $401{ }^{\circ} \mathrm{C} / \mathrm{mm}$, respectively. Thus, this method can measure different temperature gradients around the molten pool in one image frame. The 2D temperature distributions

Table 3. Shooting conditions of temperature measurement.

\begin{tabular}{|c|c|c|}
\hline Frame rate, fps & 50 & \\
\hline Resolution, pixel & $640 \times 480$ & \\
\hline Magnification, $\mu \mathrm{m} /$ pixel & 7.8 & \\
\hline Shutter speed, ms & 2 & \\
\hline Aperture & Open & \\
\hline Binning & $2 \times 2$ & \\
\hline \multirow{3}{*}{ Band-pass filter } & \multirow{2}{*}{$\begin{array}{l}\text { Two-color } \\
\text { thermometry }\end{array}$} & $\begin{array}{l}650 \mathrm{~nm} \text { (FWHM } 13 \mathrm{~nm} \text {; } \\
\text { Transmissibility } 85 \% \text { ) }\end{array}$ \\
\hline & & $\begin{array}{c}800 \mathrm{~nm} \text { (FWHM } 13 \mathrm{~nm} \text {; } \\
\text { Transmissibility } 80 \% \text { ) }\end{array}$ \\
\hline & $\begin{array}{c}\text { In-situ } \\
\text { observation }\end{array}$ & $\begin{array}{l}980 \mathrm{~nm} \text { (FWHM } 10 \mathrm{~nm} \text {; } \\
\text { Transmissibility } 50 \% \text { ) }\end{array}$ \\
\hline
\end{tabular}

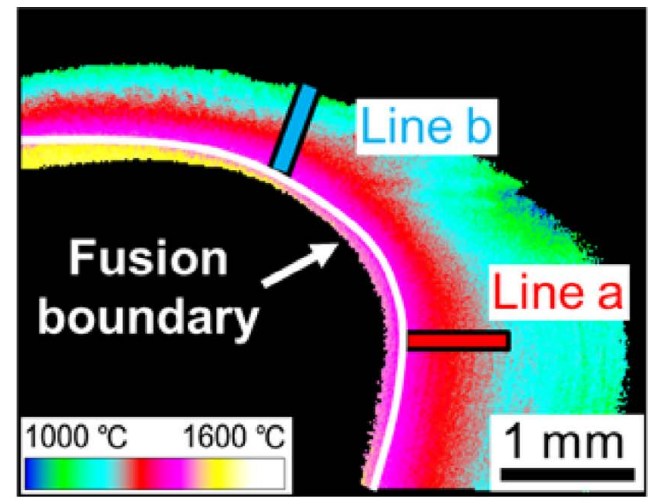

(b) 2D temperature distribution

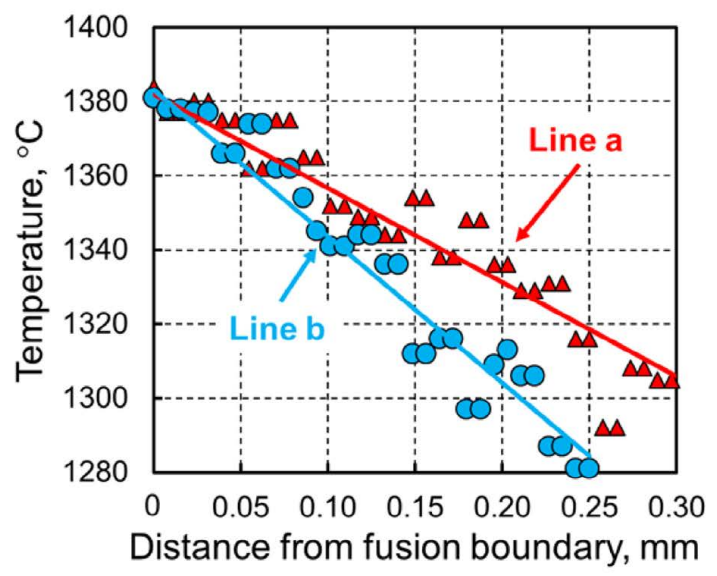

(c) Temperature gradients

Fig. 3. In-situ observation image, $2 \mathrm{D}$ temperature distribution image and temperature gradient during laser beam welding at welding speed of $0.2 \mathrm{~m} / \mathrm{min}$. (a) In-situ observation image, (b) 2D temperature distribution, (c) Temperature gradients. (Online version in color.) 
at high welding speeds of 1.0 and $2.0 \mathrm{~m} / \mathrm{min}$ are shown in Fig. 4, wherein the temperature distribution of only part of the molten pool backend can be measured at these high welding speeds because of the small measurement area of the multi-sensor camera. According to these results, the 2D temperature distributions can be measured not only at low welding speed but also at high welding speeds. In this study, only one side of $2 \mathrm{D}$ temperature distribution was used for measuring the temperature range of the solidification crack owing to the symmetric temperature distribution.

3.2. Two-dimensional Temperature Distribution Measurement Method for Measuring Temperature Range of the Crack

The temperature measurement method should be verified because the measured temperature range of the crack could be affected by a scattered 2D temperature distribution. Figure 5 shows the relationship between the angle to welding direction and temperature gradient at welding speeds of 0.2 and $1.0 \mathrm{~m} / \mathrm{min}$. In Fig. 5, the triangle, diamond and square data points represent the temperature gradients along normal direction of the molten pool. These temperature gradients are measured vertical to the fusion boundary using different frame images of the 2D temperature distribution during the steady state to investigate the temperature gradient error range. Moreover, the regression curve is performed using the least squares method. At low welding speed of $0.2 \mathrm{~m} / \mathrm{min}$, the temperature gradients can be measured at different angles from 0 to $90^{\circ}$ since the molten pool shape is a smooth curve, as shown in Figs. 5(a) and 3(a). However, at high welding speed of $1.0 \mathrm{~m} / \mathrm{min}$, most of the temperature gradient values appear at the angle between 60 and $80^{\circ}$ because of a teardrop-shaped molten pool, as shown in Figs. 5(b) and 4(a). Similar results also appear at high welding speeds of 1.5 and $2.0 \mathrm{~m} / \mathrm{min}$.

Figure 6 shows relationship between the angle to welding direction and the average temperature gradient along the normal direction of the molten pool at different welding speeds. Except for the average value at the angles of 0 and $90^{\circ}$, the average values are obtained at $10^{\circ}$ interval, while the least squares method is employed to analyze the curve fitting for each welding speed. With increasing the angle, the average value increases at welding speed of $0.2 \mathrm{~m} / \mathrm{min}$. However, at welding speeds from 1.0 to $2.0 \mathrm{~m} / \mathrm{min}$, the average value is nearly same at the low angle of $0^{\circ}$ and the high angles from 60 to $80^{\circ}$.

\subsection{The Temperature Range of the Solidification Crack Using the 2D Temperature Distribution}

Figure 7 shows the solidification crack distribution at welding speed of 0.2 and $1.0 \mathrm{~m} / \mathrm{min}$ under an augmented strain of $2.8 \%$. Figures 7 (a) and 7(c) indicate SEM images of the solidification crack distributions at welding speed of 0.2 and $1.0 \mathrm{~m} / \mathrm{min}$, respectively, where the red smooth curve represents the fusion boundary and the yellow bar expresses the solidification crack distribution. Figures 7(b) and 7(d) show the solidification crack length quantitatively at welding speeds of 0.2 and $1.0 \mathrm{~m} / \mathrm{min}$. During solidification, some

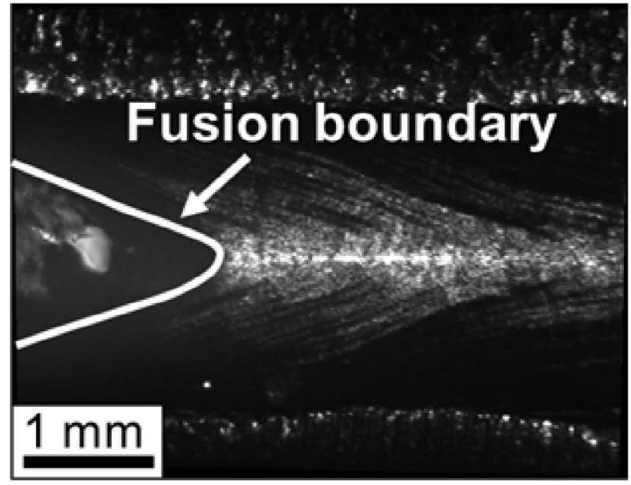

(a) In-situ observation image at $1.0 \mathrm{~m} / \mathrm{min}$

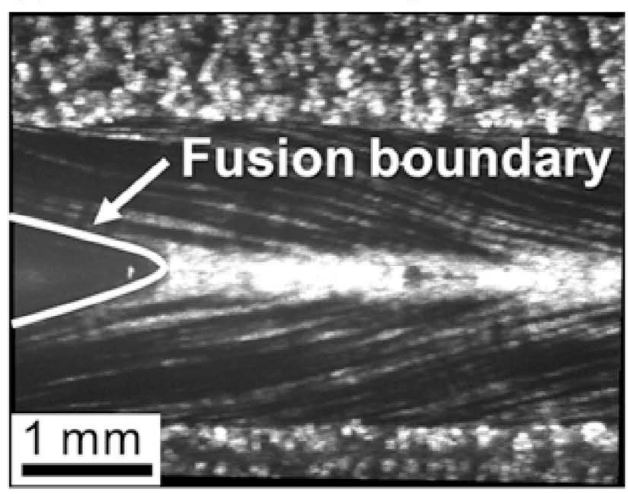

(c) In-situ observation image at $2.0 \mathrm{~m} / \mathrm{min}$

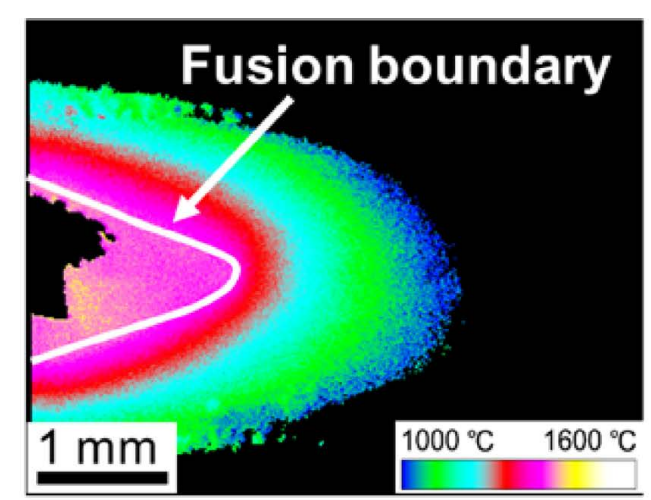

(b) 2D temperature distribution at $1.0 \mathrm{~m} / \mathrm{min}$

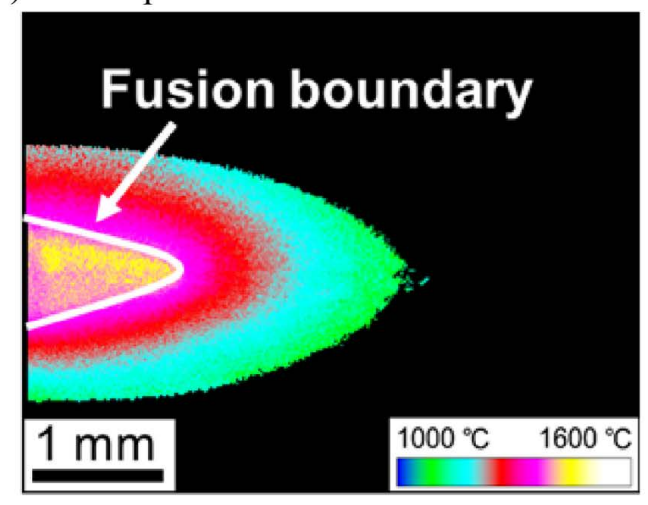

(d) $2 \mathrm{D}$ temperature distribution at $2.0 \mathrm{~m} / \mathrm{min}$

Fig. 4. In-situ observation and $2 \mathrm{D}$ temperature distribution images during laser beam welding at high welding speeds of 1.0 and $2.0 \mathrm{~m} / \mathrm{min}$. (a) In-situ observation image at $1.0 \mathrm{~m} / \mathrm{min}$, (b) $2 \mathrm{D}$ temperature distribution at $1.0 \mathrm{~m} / \mathrm{min}$, (c) In-situ observation image at $2.0 \mathrm{~m} / \mathrm{min}$, (d) $2 \mathrm{D}$ temperature distribution at $2.0 \mathrm{~m} / \mathrm{min}$. (Online version in color.) 


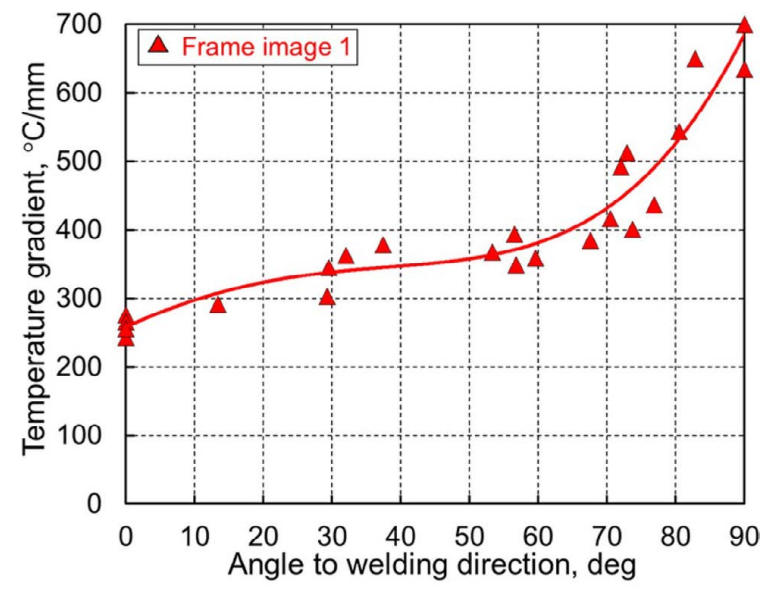

(a) Welding speed of $0.2 \mathrm{~m} / \mathrm{min}$

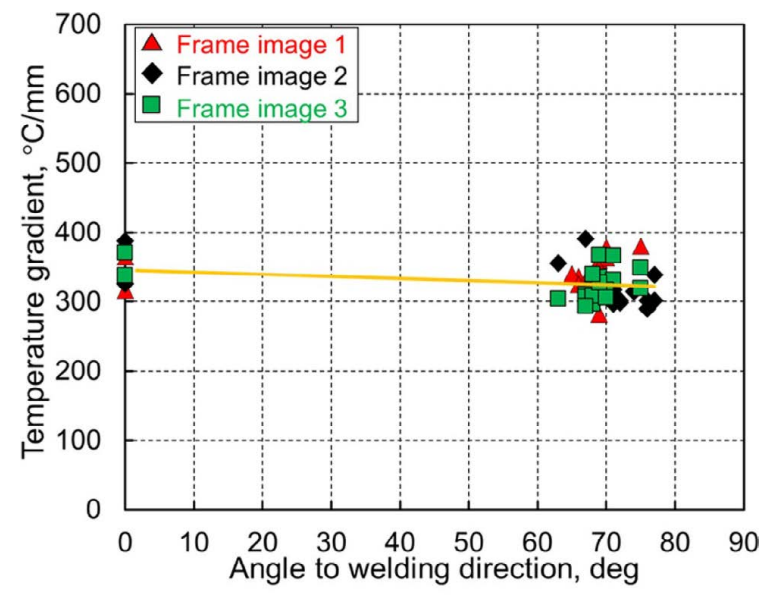

(b) Welding speed of $1.0 \mathrm{~m} / \mathrm{min}$

Fig. 5. Relationship between angle to welding direction and temperature gradient. (a) Welding speed of $0.2 \mathrm{~m} / \mathrm{min}$, (b) Welding speed of $1.0 \mathrm{~m} / \mathrm{min}$. (Online version in color.)

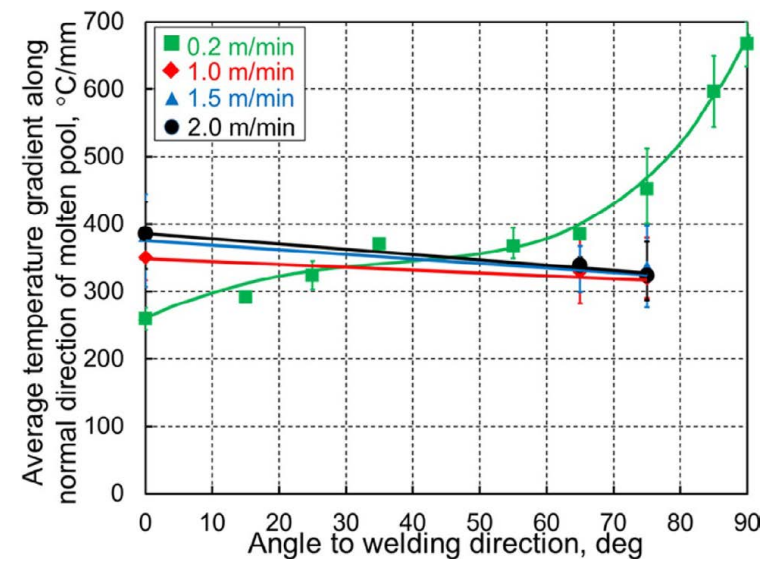

Fig. 6. Average temperature gradient along normal direction of molten pool at each welding speed. (Online version in color.)

cracks initiate from the fusion boundary, whose lengths are marked by a red bar. Additionally, a portion of some cracks near the molten pool could be healed by the liquid metal therein, and the healed part is marked in the image by a light upward bar while the crack length is marked by a red bar. Moreover, a few cracks initiate far away from fusion boundary, thus, the white bar represents the distance from the fusion boundary to the crack initiation position. By com-

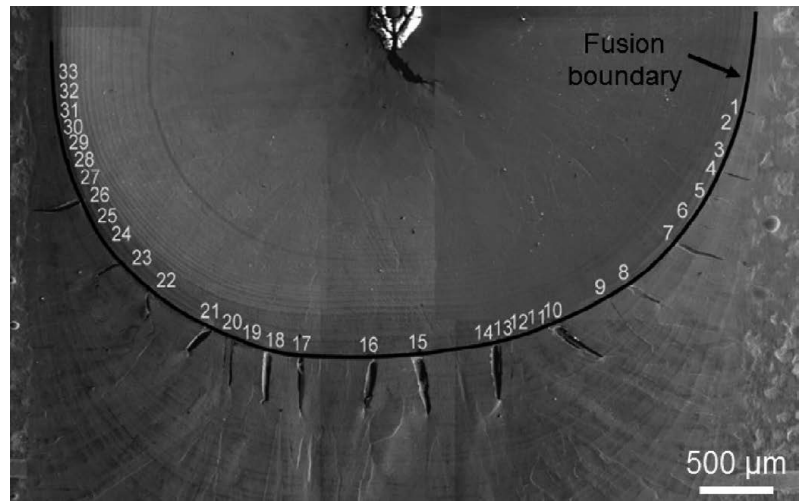

(a) SEM image of solidification crack distribution at welding speed of 0.2 $\mathrm{m} / \mathrm{min}$

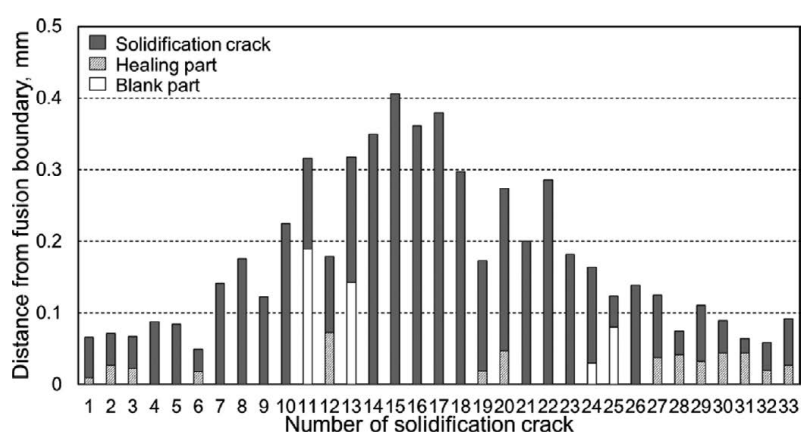

(b) Solidification crack distribution at welding speed of $0.2 \mathrm{~m} / \mathrm{min}$

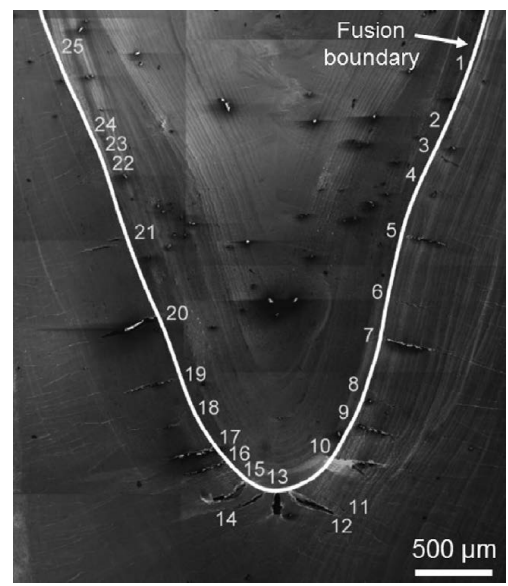

(c) SEM image of solidification crack distribution at welding speed of 1.0 $\mathrm{m} / \mathrm{min}$

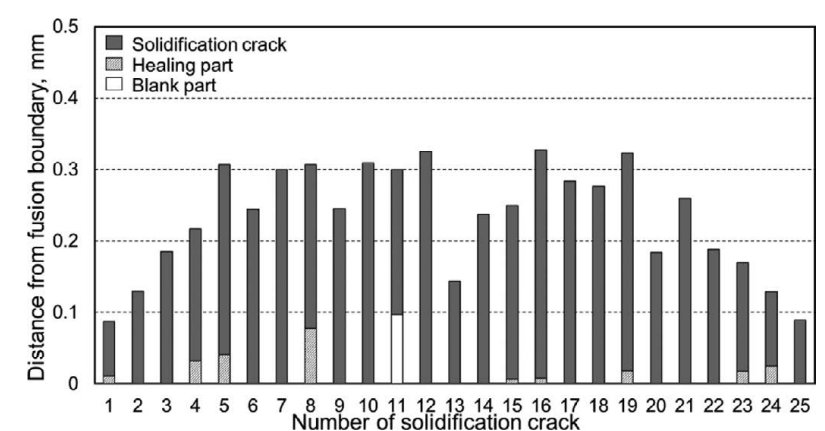

(d) Solidification crack distribution at welding speed of $1.0 \mathrm{~m} / \mathrm{min}$

Fig. 7. Solidification crack distribution at welding speeds of 0.2 and $1.0 \mathrm{~m} / \mathrm{min}$ under augmented strain of $2.8 \%$. (a) SEM image of solidification crack distribution at welding speed of $0.2 \mathrm{~m} / \mathrm{min}$, (b) Solidification crack distribution at welding speed of $0.2 \mathrm{~m} / \mathrm{min}$, (c) SEM image of solidification crack distribution at welding speed of $1.0 \mathrm{~m} / \mathrm{min}$, (d) Solidification crack distribution at welding speed of $1.0 \mathrm{~m} /$ $\min$ 
parison, the longest No. 15 crack occurs at the rear center of the molten pool at low welding speed of $0.2 \mathrm{~m} / \mathrm{min}$, while the longest No. 16 crack appears at the side of the molten pool at high welding speed of $1.0 \mathrm{~m} / \mathrm{min}$. Similar results also appear at higher welding speeds of 1.5 and $2.0 \mathrm{~m} / \mathrm{min}$.

Figure 8 illustrates the method to convert the solidification crack length to obtain the temperature range of the crack using the regression curve. The solidification crack (Black solid line) actually occurs with an angle $\theta$ to the welding direction, however the crack is not always perpendicular to the fusion boundary, as shown in Fig. 8. While, the temperature gradient is along the normal direction of the fusion boundary in the regression curve in Figs. 5 and 6 . Thus, the crack should change into one perpendicular to the fusion boundary, as illustrated by the black dashed line. At this point, the corresponding conversion length and the angel $\theta^{\prime}$ to the welding direction could be measured. Finally, the temperature range of each crack can be obtained through the conversion length of the crack, multiplying the corresponding temperature gradient at the angel $\theta^{\prime}$ using the regression curve.

Figure 9 shows the corresponding temperature range of the crack at welding speeds of 0.2 and $1.0 \mathrm{~m} / \mathrm{min}$. The temperature range is composed of that of the crack and healed crack portion length, as marked by the black bar. However, it is difficult to confirm that the crack that initiates far away from the fusion boundary is a solidification crack. Thus, to obtain the true BTR, the temperature ranges of these cracks are eliminated, such as No. 11 crack in Fig. 9(a). The maximum temperature range always distribute between 100 and $110^{\circ} \mathrm{C}$ at welding speeds of 0.2 and $1.0 \mathrm{~m} / \mathrm{min}$. In addition, this result is the same as those of welding speeds of 1.5 and $2.0 \mathrm{~m} / \mathrm{min}$.

Actually, the local strain at the high temperature under different the angles to the welding direction is an important factor to affect the initiate and the propagation of the crack during laser Trans-Varestraint test. However, it is difficult

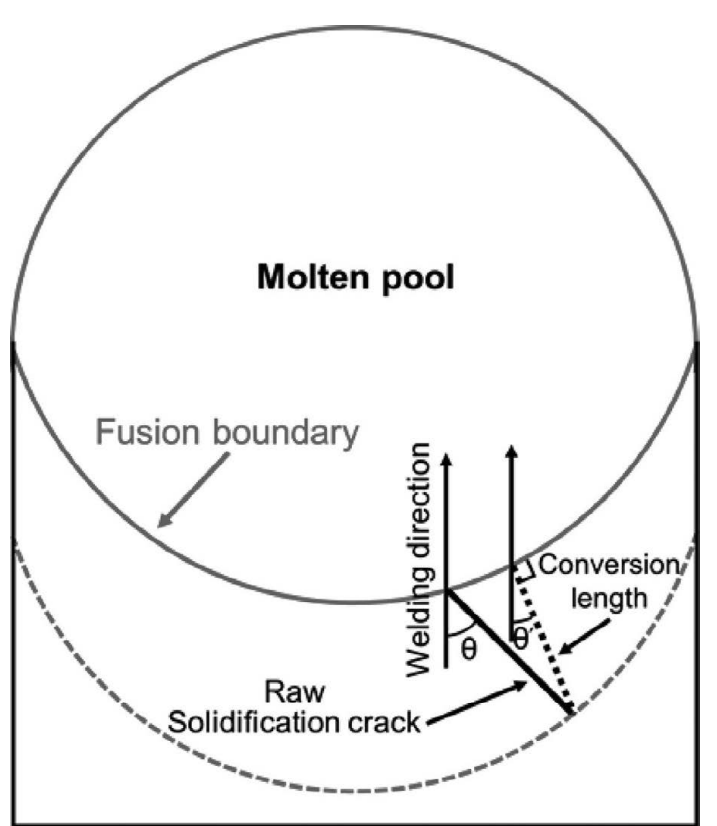

Fig. 8. Method to convert solidification crack length to obtain temperature range of the crack. to measure the local strain directly during the test. Therefore, the improvement of a new measurement method for the local strain ant the distribution is required in order to evaluate the relationship between the local strain, the angle to the welding direction and the temperature range of the crack precisely.

\subsection{Effect of Welding Speed Upon BTR}

Figure 10 shows the effect of welding speed from 0.2 to $2.0 \mathrm{~m} / \mathrm{min}$ upon the BTR during the laser Trans-Varestraint test. The BTR is the average value of the maximum temperature range of the crack under the saturated augmented strain of 2.8 and $4.3 \%$, which is almost constant around $102^{\circ} \mathrm{C}$. The result shows that welding speeds from 0.2 to

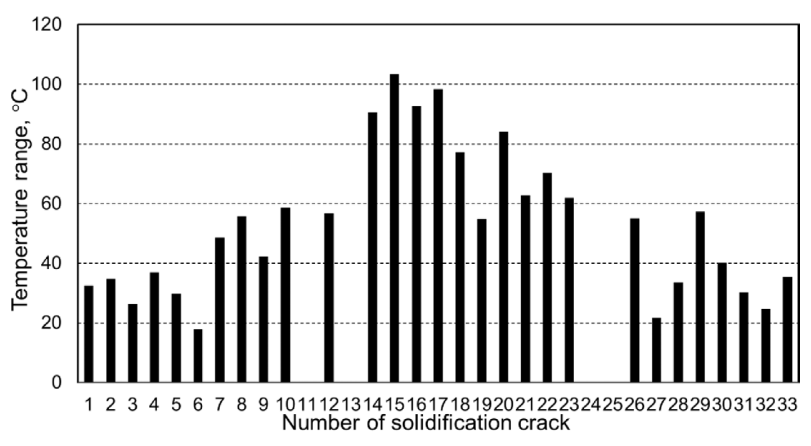

(a) Welding speed of $0.2 \mathrm{~m} / \mathrm{min}$

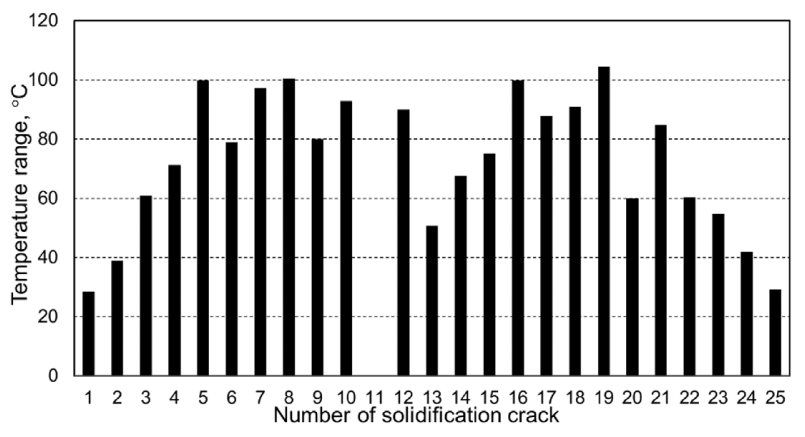

(b) Weld speed of $1.0 \mathrm{~m} / \mathrm{min}$

Fig. 9. Temperature range distribution at welding speeds of 0.2 and $1.0 \mathrm{~m} / \mathrm{min}$ under augmented strain of $2.8 \%$. (a) Welding speed of $0.2 \mathrm{~m} / \mathrm{min}$, (b) Weld speed of $1.0 \mathrm{~m} / \mathrm{min}$.

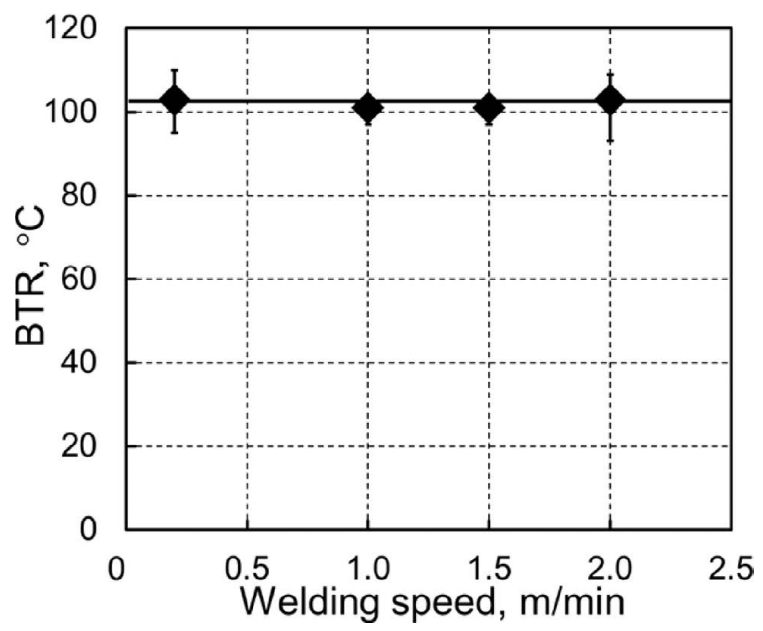

Fig. 10. Relationship between welding speed and BTR. 
$2.0 \mathrm{~m} / \mathrm{min}$ have very little influence upon the BTR. Currently, this result exhibits that with increasing welding speeds from 0.2 to $2.0 \mathrm{~m} / \mathrm{min}$, the solidification cracking susceptibility is nearly the same.

Chun et al. have reported that the BTR decreased from 133.0 to $123.6^{\circ} \mathrm{C}$ with increasing welding speed from 0.6 to $2.4 \mathrm{~m} / \mathrm{min}$ during the laser Trans-Varestraint test for type $310 \mathrm{~S}$ stainless steel due to a decrease in the liquidus temperature by undercooling and an increase in the true solidus temperature by inhibiting solidification segregation through calculation. ${ }^{5}$ ) The tendency of the BTR value is different from the author's result. From the metallurgical perspective, the segregated concentration of the impurity element, such as $\mathrm{P}$ and $\mathrm{S}$, can cause the variation of the BTR. The BTR tends to decrease with a decrease in the segregated concentration as a contribution of high cooling rate corresponding to that of welding speed. The difference of the BTR is around $10^{\circ} \mathrm{C}$ in the Chun et al. data due to the small change of the segregated concentration at different welding speeds from 0.6 to $2.4 \mathrm{~m} / \mathrm{min}$. ${ }^{5)}$ While, in this study, the deviation of the BTR is also about $10^{\circ} \mathrm{C}$ which is close to that of Chun et al., , $^{5}$ as shown in Fig. 10, therefore, it is reasonable and believable that the average BTR is nearly similar in this case. Chun et al. applied a thermocouple with a low response rate to measure the temperature profile, and the longest crack occurred at the side of molten pool during LBW at high welding speeds. In addition, the BTR was measured using the estimated temperature distribution and the conversion length of the longest crack, thus it was difficult to measure the BTR along the crack directly at the side of the molten pool. Therefore, the BTR could not be measured precisely using the thermocouple during LBW at high welding speeds owing to the high cooling rate. By comparison, the author's result has a relatively higher reliability and accuracy.

\section{Conclusions}

The solidification cracking susceptibility of type $310 \mathrm{~S}$ stainless steel was investigated using the developed laser Trans-Varestraint test and the 2D temperature measurement method. The results are as follows:

(1) The $2 \mathrm{D}$ temperature distribution for each welding speed from 0.2 to $2.0 \mathrm{~m} / \mathrm{min}$ could be measured using a multi-sensor camera based on two-color thermometry.

(2) The applicability and accuracy of the 2D temperature distribution measurement method for measuring the temperature range of the crack was evaluated quantitatively to obtain a true BTR.

(3) The temperature range of each solidification crack could be obtained using the $2 \mathrm{D}$ temperature distribution at different welding speeds.

(4) The average BTR was measured using the $2 \mathrm{D}$ temperature distribution measurement method and the average value was almost constant around $102^{\circ} \mathrm{C}$ during LBW at welding speeds from 0.2 to $2.0 \mathrm{~m} / \mathrm{min}$.

(5) The effect of welding speeds from 0.2 to $2.0 \mathrm{~m} / \mathrm{min}$ upon the solidification cracking susceptibility was very small during LBW.

\section{REFERENCES}

1) X. Na: Laser Welding, Sciyo, Croatia, (2010), 49.

2) K. Kadoi, A. Fujinaga, M. Yamamoto and K. Shinozaki: Weld. World, 57 (2013), 383

3) S. Kou: Welding Metallurgy, John Wiley \& Sons, New Jersey, (2003), 276.

4) Y. Arata, F. Matsuda, K. Nakata and I. Sasaki: Trans. JWRI, 5 (1976), 153.

5) E. J. Chun, H. Baba, K. Nishimoto and K. Saida: Met. Mater. Int., 21 (2015), 543

6) S. Yamashita, A. Fujinaga, M. Yamamoto, K. Shinozaki, K. Kadoi, K. Mitsui and H. Usui: Q. J. Jpn. Weld. Soc., 31 (2013), 78.

7) D. Wang, S. Sakoda, K. Kadoi, K. Shinozaki and M. Yamamoto: $Q$. J. Jpn. Weld. Soc., 33 (2015), 39

8) S. Yamashita, M. Yamamoto, K. Shinozaki, K. Kadoi, K. Mitsui and H. Usui: Q. J. Jpn. Weld. Soc., 33 (2015), 93. 